\title{
Temporomandibular Joint Disorder
}

National Cancer Institute

\section{Source}

National Cancer Institute. Temporomandibular Joint Disorder. NCI Thesaurus. Code C63709.

Any condition affecting the anatomic and functional characteristics of the temporomandibular joint. 